\title{
CIRCULATING FILARIAL ANTIGEN IN SERUM AND HYDROCELE FLUID FROM INDIVIDUALS LIVING IN AN ENDEMIC AREA FOR BANCROFTIAN FILARIASIS
}

\author{
*AP Shah, SA Mulla
}

\begin{abstract}
This study examined circulating filarial antigen by monoclonal antibody Og4C3-enzyme-linked immunosorbent assay (ELISA) from 114 men with hydrocele, living in an endemic area. Nocturnal blood and hydrocele fluid were collected and examined for microfilaria. ELISA was performed on serum and hydrocele fluid for detection of antigen. Amongst 114 cases, 5(4.4\%) showed microfilaria in blood but none in fluid. ELISA was positive in $13(11.40 \%)$ serum and $5(4.4 \%)$ fluid samples. All five fluid antigen positive cases were positive for antibodies and showed microfilaria in blood. These findings emphasize the use of circulating filarial antigen detection and alternative usage of hydrocele fluid for diagnosis of filariasis.
\end{abstract}

Key words: Wuchereria bancrofti, Og4C3 antigen, hydrocele fluid, lymphatic filariasis

Lymphatic filariasis, caused by the nematode Wuchereria bancrofti is a major public health and socioeconomic problem in tropical and subtropical countries. ${ }^{1}$ It is estimated that close to 120 million people are affected in at least 80 countries throughout the tropics and subtropics. ${ }^{2}$ More than 40 million people suffer from chronic form of the disease (lymphoedema, elephantiasis or scrotal hydrocele) caused by this nematode. One of the chronic consequences in $40-50 \%$ of men living in the highly endemic areas is testicular hydrocele. ${ }^{3}$ For several decades, the only traditional way to diagnose the filarial infection caused by W.bancrofti was by examining blood collected during the night. ${ }^{4}$ The detection of circulating filarial antigen (CFA), created new alternative method in the diagnosis of bancroftian filariasis. ${ }^{5}$

Monoclonal antibody, $\mathrm{mAb} \mathrm{Og} 4 \mathrm{C} 3$ has been used in the detection of specific $W$. bancrofti CFA. The great advantage of using CFA for diagnosis is the fact that CFA levels remain the same during the $24 \mathrm{~h}$ of the day, avoiding the need to collect blood samples at night. ${ }^{6}$

The present study aims at detection of filarial infection using buffy coat concentration technique and enzyme-linked immunosorbent assay (ELISA), in hydrocele patients living in Surat district, which is a known filariasis endemic area in Gujarat state. We also aimed to evaluate the use of hydrocele fluid in the diagnosis of $W$. bancrofti infection using the CFA detected by $\mathrm{mAb} \mathrm{Og} 4 \mathrm{C} 3$.

\footnotetext{
*Corresponding author (email: <draartishah@yahoo.co.uk>) Department of Microbiology, Government Medical College and New Civil Hospital, Surat - 395 001, Gujarat, India

Received: 03-04-06

Accepted: 25-03-07
}

\section{Materials and Methods}

\section{Inclusion criteria}

The study was carried out between August 2003 and August 2004. The ethical committee of the hospital approved the study. One hundred and fourteen individuals with testicular hydrocele, admitted in the surgical ward, were analyzed and examined by WHO standard criteria. Before the collection of blood samples, participants were examined and found to have no clinical symptoms of filariasis except hydrocele and also were not having any other chronic illness specifically tuberculosis, leprosy, diabetes and hypertension.

\section{Sample collection}

After taking the informed consent, we collected one millilitre each venous blood in one EDTA tube and one plain tube. Blood samples were collected between 20:00 hours and 22:00 hours. Capillary buffy coat concentration technique was performed from the EDTA sample and thick smear was prepared and stained by Giemsa stain using standard methods. Hydrocele fluid $(5 \mathrm{~mL})$ was collected in the operation theatre during hydrocele surgery and immediately transferred to the laboratory for further processing. On receiving the fluid, buffy coat concentration technique was performed for detection of microfilaria. Paired samples of serum and hydrocele fluid were stored at $-20^{\circ} \mathrm{C}$ until usage. Monoclonal antibody, $\mathrm{mAb}$ $\mathrm{Og} 4 \mathrm{C} 3$, was used in the detection of specific $W$. bancrofti $\mathrm{CFA}$. The murine mAb $\mathrm{Og} 4 \mathrm{C} 3$ is a mAb raised against the nematode Oncocerca gisbsoni (manufactured by Tropbio Pvt Ltd., Queensland, Australia). The ELISA test was performed according to manufacturer's guidelines, simultaneously on all serum and hydrocele fluid samples, after pre-treatment by boiling. The results were recorded as optical density (OD), using $414 \mathrm{~mm}$ filter. OD for high titre reference antigen is not 
Table: Relationship between circulating filarial antigen and microfilariae detection in different samples

\begin{tabular}{|c|c|c|c|c|c|c|}
\hline \multirow[t]{2}{*}{ Samples } & \multirow{2}{*}{$\begin{array}{c}\text { No. of } \\
\text { cases }\end{array}$} & \multicolumn{5}{|c|}{ Test results } \\
\hline & & $\mathrm{CFA}+, \mathrm{MF}+$ & $\mathrm{CFA}+, \mathrm{MF}-$ & CFA-,MF+ & CFA-,MF- & Total \\
\hline Serum & 114 & 05 & 08 & 00 & 101 & 114 \\
\hline Hydrocele fluid & 114 & 00 & 05 & 00 & 109 & 114 \\
\hline Total & 228 & 05 & 13 & 00 & 210 & 228 \\
\hline
\end{tabular}

$P$ value $\sim 0.0001$ in both serum and hydrocele fluid (McNemar Chi square test), CFA - Circulating filarial antigen, MF - Microfilariae

less than 1.1 and OD for non-reactive reference antigen is not more than 0.3. Samples recording OD higher than the nonreactive reference antigen were considered positive.

McNemar Chi square test was performed to evaluate the two methods.

\section{Results}

A total of 114 men with testicular hydrocele, aged between 18 to 70 years (mean age 30 years) were involved in this study. The majority of patients were in the age group of 21 to 30 years $(35 \%)$, followed by 31 to 40 years $(21 \%)$.

Efficacy comparison of two testing methods (Table) was done by using McNemar Chi square test. It was observed that in serum samples $(n=114), O g 4 C 3$-ELISA could detect infection in $13(11.40 \%)$ individuals, while night blood smear could detect in $5(4.40 \%)$. In hydrocele fluid sample, the detection rate was $5(4.40 \%)$ and $0(0 \%)$ by CFA-ELISA and conventional night blood smear respectively. Infection rate detected by CFA assay was significantly higher $(P \sim 0.0001)$ compared to that by night blood smear examination.

It was observed that all five patients showing microfilaria in their blood were positive for CFA in hydrocele fluid and also the same patients were positive for CFA in serum.

All the microfilaraemic individuals were positive for CFA in blood as well as for CFA in hydrocele fluid, while all CFA positive individuals were not positive for microfilaria in blood. Out of 114 cases, five $(4.40 \%)$ were microfilaraemic and also CFA positive in both serum and hydrocele fluid, while there were eight cases who were CFA positive in blood but negative for CFA in hydrocele fluid and also negative for microfilaria in blood.

\section{Discussion}

In the past several decades, many researchers have been interested in utilizing the hydrocele fluid to obtain and isolate CFA from $W$. bancrofti. The use of the hydrocele fluid became a tool of value in diagnosing individuals with $W$. bancrofti infection due to the straightforward procedure to obtain fluid in ambulatory punctions or in the hydrocelectomies. ${ }^{7}$

Recently, the availability of monoclonal antibodies, $\mathrm{Og} 4 \mathrm{C} 3$ and $\mathrm{AD} 12$, which can be used in ELISA and immunochromatography respectively, have become important for filariasis diagnosis in biological fluids. Hassan et al., ${ }^{8}$ using the mAb AD12-ELISA, were able to identify CFA from paired samples of sera and hydrocele fluids in $50 \%$ and $66.7 \%$ of the microfilaria negative and microfilaria positive men with hydrocele, respectively. However, the our results demonstrate that the $\mathrm{mAb} O \mathrm{Og} 4 \mathrm{C} 3$-ELISA can be used as a diagnostic tool in filariasis, since through this technique CFA was detected in $61.5 \%$ of microfilaria negative cases. This fact must be taken in to consideration by those involved in filariasis control programs.

The present study demonstrates 2.5 times higher CFA positivity in blood than microfilaria positivity indicating that a majority of the infections was antigen positive but microfilaria negative. Since the sample size is very small, this study needs further evaluation on a large scale.

Studies from More and Copeman, ${ }^{9}$ and Lalitha et al. ${ }^{10}$ concluded that the $\mathrm{mAb} \mathrm{Og} 4 \mathrm{C} 3$ detects CFA from adult worms, excluding the contribution of microfilaria in the production of CFA. Many studies do not agree with this hypothesis. ${ }^{111}$ These authors demonstrated on the contrary that the CFA intensity is directly proportional to the microfilaraemia density, i.e, the higher the microfilaria density, the higher the CFA level. Present study demonstrates that microfilaraemic individuals were all positive for CFA assay on both serum and hydrocele fluid. This finding may be because of higher microfilarial density which needs further evaluation.

Our results showed the possibility of using the hydrocele fluid in order to enhance the diagnosis of individuals affected with the $W$. bancrofti infection. ${ }^{12}$ Moreover, both sera and fluid samples from all microfilaria positive individuals were positive using the CFA assay. These data are of great interest, since the hydrocele fluid collected during the emptying of the scrotal area is always discarded in both ambulatory procedures and hydrocelectomies. The finding that all microfilaraemic individuals are CFA positive in hydrocele fluid could help in the quick diagnosis and treatment of the infection.

\section{References}

1. Rocha A, Lima G, Medeiros Z, Aguiar-Santos A, Alves S, Montarroyos U, et al. Circulating filarial antigen in the hydrocele fluid from individuals living in a bancroftian filariasis area 
- Recife, Brazil: Detected by the monoclonal antibody Og4C3assay. Mem Inst Oswaldo Cruz 2004;99:101-5.

2. Shenoy R. Lymphatic filariasis in children. Indian J Lymphology 2003;1:7-13.

3. Kumaraswami V. The clinical manifestations of lymphatic filariasis. In: Nutman TB, editor. Lymphatic Filariasis. Imperial College Press: London; chap. 5, 2000. p. 103-25.

4. WHO-World Health Organization 1984. Lymphatic filariasis fourth report of the WHO expert committee on filariasis. WHO technical reports series 702 .

5. Weil GJ, Jain DC, Santhanam S, Malhotra A, Kumar H, Sethumadhavan KV, et al. A monoclonal antibody-based enzyme immunoassay for detecting parasite antigenemia in bancroftian filariasis. J Infect Dis 1987;156:350-5.

6. Lammie PJ, Hightower AW, Eberhard ML. The age-specific prevalence of antigenemia in a Wuchereria bancrofti-exposed population. Am J Trop Med Hyg 1994;51:348-55.

7. Ramaprasad P, Harinath BC. Fraction, characterization and diagnostic potential of filarial antigens isolated from hydrocoele fluid in bancroftian filariasis. Trans $\mathrm{R}$ Soc Trop Med Hyg 1989;83:90-4.
8. Hassan MM, Ata M, Ramzy RM, el-Gendi AE, Hegab MH, Gabr $\mathrm{NS}$, et al. Evaluating the detection of circulating filarial antigen in diagnosis of bancroftian filariasis and filarial hydrocele. J Egypt Soc Parasitol 1996;26:687-96.

9. More SJ, Copeman DB. A highly specific and sensitive monoclonal antibody-based ELISA for the detection of circulating antigen in bancroftian filariasis. Trop Med Parasitol 1990;41:403-6.

10. Lalitha P, Ravichandran M, Suba S, Kaliraj P, Narayanan RB, Jayaraman K. Quantitative assessment of circulating antigens in human lymphatic filariasis: A field evaluation of monoclonal antibody-based ELISA using blood collected on filter strips. Trop Med Int Health 1998;3:41-5.

11. Rocha A, Addiss D, Ribeiro ME, Norões J, Baliza M, Medeiros $\mathrm{Z}$, et al. Evaluation of the OG4C3 ELISA in Wuchereria bancrofti infection: Infected persons with undetectable or ultra-low microfilarial densities. Trop Med Int Health 1996;1:859-64.

12. Dreyer G, Addiss D, Roberts J, Norões J. Progression of lymphatic vessel dilation in presence of living adult Wuchereria bancrofti. Trans R Soc Trop Med Hyg 2002;96:157-61.

Source of Support: Nil, Conflict of Interest: None declared. 